\title{
Is Age Associated With the Severity of Post-Mild Traumatic Brain Injury Symptoms?
}

\author{
Tina Hu, Cindy Hunt, Donna Ouchterlony
}

\begin{abstract}
Background: Mild traumatic brain injury (mTBI) is a significant public health concern. Research has shown that mTBI is associated with persistent physical, cognitive, and behavioural symptoms, leading to significant direct and indirect medical costs. Our objective was to determine if age impacts the type and severity of post-mTBI symptoms experienced. Methods: Retrospective analysis of prospectively collected data at a level 1 tertiary care outpatient head injury clinic. Participants $(\mathrm{N}=167)$ were patients seen at the clinic following an mTBI. The Rivermead Post-Concussion Symptoms Questionnaire was used to assess symptom severity. Results: In our sample, the mean age was $44 \pm 16$ years with $51 \%$ males. Compared with other age groups, patients $>66$ years of age were significantly more likely to report an mTBI between 6 AM to 12 PM (69\%). Middle-aged patients (36-55 years) were more likely to report higher severity of certain post-mTBI symptoms (headache, nausea and vomiting, irritability, poor concentration, sleep disturbance, blurry vision, light sensitivity, and taking longer to think) compared with patients $>66$ years of age. Conclusions: In general, middle-aged patients reported higher severity of post-mTBI symptoms compared with the oldest patients. Thus, there was a significant association between age and the severity of specific mTBI symptoms, which highlights the need for targeted management. Additional research is needed to understand the mechanisms that could be contributing to the higher symptom severity experienced by the middle-aged group.
\end{abstract}

RÉSUMÉ: L’âge est-il associé à la sévérité des symptômes suite à un traumatisme crânien léger? Contexte: Le traumatisme crânien léger (TCL) constitue une préoccupation importante en santé publique. La recherche a montré que le TCL entraîne des symptômes physiques, cognitifs et comportementaux persistants, générant des coûts médicaux directs et indirects importants. Notre objectif était de déterminer si l'âge a un impact sur le type et la sévérité des symptômes post TCL chez un patient. Méthodologie: Nous avons effectué une analyse rétrospective de données recueillies prospectivement à une clinique externe de traumatisme crânien dans un centre de soins tertiaires de niveau 1. Les participants $(\mathrm{N}=167)$ étaient des patients référés à la clinique après un TCL. Nous avons utilisé le Rivermead Post-Concussion Symptoms Questionnaire pour évaluer la sévérité des symptômes Résultats: L'âge moyen des patients de notre échantillon était de $44 \pm 16$ ans, dont $51 \%$ étaient des hommes. Les patients de plus de 66 ans étaient significativement plus susceptibles de rapporter un TCL entre 6 AM et 12 PM (69\%) par rapport aux patients des autres groupes d'âge. Les patients d'âge moyen (36 à 55 ans) était plus susceptibles de rapporter que certains symptômes post TCL étaient plus sévères (céphalée, nausées et vomissements, irritabilité, difficulté à se concentrer, troubles du sommeil, vision embrouillée, sensibilité à la lumière et idéation lente) que les patients de plus de 66 ans. Conclusions: En général, les patients d'âge moyen ont rapporté que la sévérité de leurs symptômes post-TCL était plus importante que celle rapportée par les patients plus âgés. Il y avait donc une association significative entre l'âge et la sévérité des symptômes spécifiques du TCL, ce qui souligne l'importance d'une gestion ciblée de ces symptômes. D'autres études devront être réalisées pour comprendre les mécanismes qui pourraient contribuer à la plus grande sévérité des symptômes éprouvés par le groupe de patients d'âge moyen.

Keywords: Head Trauma, Brain Injury-Traumatic

doi:10.1017/cjn.2016.441

Can J Neurol Sci. 2017; 44: 384-390

Traumatic brain injury (TBI) is the leading cause of mortality and morbidity in the world for individuals younger than age $45 .{ }^{1}$ Mild TBI (mTBI) accounts for approximately $70 \%$ to $90 \%$ of all TBIs and is a major source of morbidity in up to $15 \%$ of patients experiencing long-term symptoms. ${ }^{2-5}$ Data have shown that age plays a significant role in mTBI incidence, with a bimodal distribution with peaks occurring in young adulthood (15-19 years) and those $>65$. Different age groups experience different injury mechanisms: falls are responsible for more than $50 \%$ of TBI among individuals older than age 65 , whereas motor vehicle accidents are the leading cause of TBI-related mortality in young adults. ${ }^{6,8}$

It is generally believed that increased age leads to worse health outcomes following TBI. This may be due to several reasons: older adults may have less complete recovery compared with younger individuals with comparable injuries because of less capacity for compensation, older patients may be at higher risk for progressive cognitive decline after TBI because of age-related reductions in cerebral reserve, and older patients may be at higher risk for complications because of preexisting comorbidities. ${ }^{9-11}$ However, the

From the Faculty of Medicine, University of Toronto, Toronto, Ontario, Canada (TH), Head Injury Clinic, St. Michael's Hospital, Toronto, Ontario, Canada (CH, DO).

Received July 13, 2016. Final Revisions Submitted October 6, 2016. Date of ACCEPTANCE NOVEMBER 7, 2016.

Correspondence to: Tina Hu, Head Injury Clinic, St. Michael's Hospital, 30 Bond Street, Toronto, Ontario M5B 1W8, Canada. Email: tina.hu@mail.utoronto.ca 
literature is unclear on whether age affects mTBI outcomes: some studies have suggested that increased age leads to worse outcomes, but other studies have shown that older adults actually do better than younger individuals on global outcome measures. ${ }^{7,12-16}$ Thus, the discriminating effects of age on mTBI outcomes is uncertain.

mTBI symptoms are broadly categorized into three domains: physical (headache, nausea, vomiting), behavioural/emotional (fatigue, depression), and cognitive (memory changes). mTBI can often cause persistent symptoms and long-term disability, which can have detrimental effects on the patient's life, occupation, and psychosocial functioning. ${ }^{17}$ Several studies have examined the impact of age on post-mTBI symptoms, but results are inconclusive: some studies indicated that older age is associated with greater severity of cognitive symptoms, whereas other studies have suggested that there are no differences in type or severity of postmTBI symptoms between young and older age groups. $7,13,15,17-20$ This study aims to primarily examine age and its association with mTBI symptomatology and severity using a validated mTBI symptom questionnaire, with the goal of guiding clinical practice with respect to assessments and interventions.

\section{Methods}

\section{Participants}

This study was approved by the Research Ethics Board of St. Michael's Hospital (Toronto, Ontario, Canada). The population in this study was 167 patients seen at the Head Injury Clinic (HIC), a level 1 tertiary outpatient clinic at St. Michael's Hospital from June 2013 to January 2015, who met the criteria for mTBI and were $>16$ years of age. For this study, we used the definition of mTBI created by the American Congress of Rehabilitation Medicine. mTBI was defined as a "traumatically induced physiologic disruption of brain function including at least 1 of the following: any period of loss of consciousness, any loss of memory for events immediately before or after the accident (post-traumatic amnesia), any alteration in mental state at the time of accident (feeling disoriented, dazed, or confused), or focal neurological deficits, but where the severity of the injury did not exceed the following: loss of consciousness of 30 minutes or less, an initial Glasgow Coma Scale of 13-15 after 30 minutes, and post-traumatic amnesia not greater than 24 hours." 21

\section{Study Instruments}

Upon their first visit to the HIC, patients were required to complete the HIC Screening Tool, which collected information on demographics, place of injury, injury mechanism, mTBI characteristics, and comorbidities. The HIC Screening Tool was designed using common data elements for TBI from several internationally recognized sources such as the National Institute of Neurological Disorders and Stroke and the Ontario Neurotrauma Foundation Clinical Guidelines, with the goal of ensuring standardization in data collection for a better understanding of mTBI diagnosis and prognosis. ${ }^{22}$ All patients completed the Rivermead Post-Concussion Symptoms Questionnaire (RPQ), which was intended to give insight into the severity of 16 postconcussion symptoms that patients may be experiencing. In the RPQ, there were five response alternatives on an ordinal level that patients used to indicate the degree to which symptoms are more of a problem compared to preinjury levels. The RPQ has been shown to measure severity of postconcussion symptoms reliably with good test-retest and inter-rater reliability for individual symptom scores. ${ }^{23}$ Current research has suggested splitting the RPQ into two subscale scores: RPQ-3 uses the sum of scores from three items (headaches, dizziness, and nausea) and RPQ-13 uses the sum of scores of the other 13 items. $^{24,25}$ Higher scores especially for the RPQ-13 subscale are associated with greater impact on lifestyle. ${ }^{25}$

Table 1: Characteristics of participants by age group

\begin{tabular}{|c|c|c|c|c|c|c|c|}
\hline & $\begin{array}{l}16-25 \text { years } \\
(n=27)\end{array}$ & $\begin{array}{l}26-35 \text { years } \\
\quad(n=31)\end{array}$ & $\begin{array}{c}\text { 36-45 years } \\
(n=29)\end{array}$ & $\begin{array}{l}\text { 46-55 years } \\
\quad(n=42)\end{array}$ & $\begin{array}{c}\text { 56-65 years } \\
(n=24)\end{array}$ & $\begin{array}{c}66+\text { years } \\
(n=14)\end{array}$ & p value \\
\hline Gender ( $\%$ female $)$ & 56 & 39 & 48 & 48 & 50 & 57 & 0.82 \\
\hline Highest education (\%) & & & & & & & 0.35 \\
\hline Less than high school & 24 & 15 & 7.4 & 12 & 4.8 & 29 & \\
\hline High school & 28 & 19 & 11 & 18 & 19 & 21 & \\
\hline Postsecondary studies & 48 & 67 & 82 & 70 & 76 & 50 & \\
\hline Country of birth (\% Canada) & 85 & 74 & 81 & 73 & 38 & $42 *$ & $0.002 *$ \\
\hline Language at home (\% English) & 85 & 96 & $92 \%$ & 100 & 90 & 75 & 0.08 \\
\hline Living alone (\%) & 3.8 & 15 & 16 & 27 & 43 & $54 *$ & $0.002 *$ \\
\hline Living with children $<21$ years of age $(\%)$ & 3.8 & 11 & $46 \dagger$ & 33 & 9.5 & 0 & $<0.001 \dagger$ \\
\hline Employed preinjury (\%) & 64 & 89 & 92 & $94 \%$ & $85 \%$ & $50 *$ & $0.001 *$ \\
\hline Current employment status & & & & & & & $<0.001 \dagger$ \\
\hline$\%$ working & 25 & 38 & 44 & 39 & 30 & 23 & \\
\hline$\%$ sick leave/laid off & 8.3 & 17 & $11.1 \%$ & 6.1 & 10 & 0 & \\
\hline$\%$ unemployed & 4.2 & 4.2 & 11.1 & 6.1 & 5.0 & 0 & \\
\hline$\%$ disabled & 29 & 33 & 33 & 46 & 40 & 0 & \\
\hline$\%$ retired & 0 & 0 & 0 & 0 & 15 & $70 \dagger$ & \\
\hline
\end{tabular}

$\mathrm{p}<0.01 ; \uparrow \mathrm{p}<0.001$. Data were analyzed using chi-square analyses with Bonferroni post-hoc testing. 


\section{Statistical Analysis}

All data were analyzed using SPSS. For these analyses, patients were separated into age groups (16-25, 26-35, 36-45, $46-55,56-65$, >66 years). Descriptive analyses using chi-square analyses with Bonferroni corrections were used to examine characteristics of each age group in terms of determinants of health preinjury as well as characteristics of the mTBI event. Ordinal logistic regressions were used to determine the odd ratios of severe post-mTBI symptoms in each age group while controlling for days since injury, gender, and injury mechanism. Forward stepwise linear regressions were used to determine the odds ratio of higher RPQ subscale scores in relation to increasing age. Significance was assigned at $\mathrm{p}<0.05$.

\section{RESULTS}

\section{Characteristics of Participants}

A total of 167 patients seen at the HIC met the American Congress of Rehabilitation Medicine criteria for mTBI and were included in the study. Descriptive statistics for patient characteristics by age group are shown in Table 1 . The mean age in the overall sample was $44 \pm 16$ years (51\% males). Approximately $50 \%$ of the oldest age group was employed preinjury, which was significantly lower compared with other age groups $(\mathrm{p}=0.001)$. A total of $46 \%$ of the 36 - to 45 -year-old age group reported living with children younger than 21 years old, which was higher compared with other age groups $(\mathrm{p}<0.001)$. There were no significant differences in comorbidities across age groups ( $p>0.05$ for all).

\section{mTBI Characteristics}

Descriptive statistics for mTBI time and mechanisms are shown in Table 2. Sixty-nine percent of mTBI in the oldest age group occurred during the morning (6 AM-12 PM), which was a significantly higher proportion compared with all other age groups $(\mathrm{p}=0.001)$. There were no significant differences in injury mechanism between age groups $(p=0.34)$. The average time from mTBI to first medical evaluation at the HIC was approximately 317 days. There were no significant differences in time from mTBI to medical evaluation at the HIC between age groups $(p=0.87)$. There were no differences in mTBI characteristics or associated injuries between age groups as shown in Table 3.

\section{Predictors of Severity of Post-mTBI Symptoms}

In general, age was found to be a significant predictor of the severity of several symptoms experienced post-mTBI, with middle-aged patients reporting more severe symptoms compared with the oldest patient group. All age groups were more likely to report a severe headache and nausea/vomiting over not experiencing at all compared with patients $>66$ years old $(\mathrm{p}<0.05$ for all).

Table 2: mTBI time and mechanisms by age group

\begin{tabular}{|c|c|c|c|c|c|c|c|}
\hline & $\begin{array}{c}16-25 \text { years } \\
(n=27)\end{array}$ & $\begin{array}{c}26-35 \text { years } \\
(n=31)\end{array}$ & $\begin{array}{c}36-45 \text { years } \\
(n=29)\end{array}$ & $\begin{array}{c}\text { 46-55 years } \\
(n=42)\end{array}$ & $\begin{array}{c}\text { 56-65 years } \\
(\mathrm{n}=24)\end{array}$ & $\begin{array}{c}66+\text { years } \\
(n=14)\end{array}$ & p value \\
\hline Mean days since injury until seen at clinic & $287 \pm 263$ & $346 \pm 263$ & $286 \pm 229$ & $306 \pm 304$ & $358 \pm 234$ & $352 \pm 280$ & 0.87 \\
\hline Season in which injury occurred $(\%)$ & & & & & & & 0.22 \\
\hline Spring & 33 & 19 & 17 & 22 & 46 & 14 & \\
\hline Summer & 26 & 19 & 21 & 32 & 13 & 43 & \\
\hline Fall & 26 & 36 & 21 & 29 & 21 & 21 & \\
\hline Winter & 15 & 26 & 41 & 17 & 21 & 21 & \\
\hline Time in which injury occurred $(\%)$ & & & & & & & $0.001 *$ \\
\hline 6 AM-12 PM & 33 & 9.1 & 25 & 21 & 28 & $69 *$ & \\
\hline 12 PM-6 PM & 24 & 14 & 46 & 53 & 39 & 23 & \\
\hline $6 \mathrm{PM}-12 \mathrm{AM}$ & 19 & 50 & 17 & 18 & 28 & 0 & \\
\hline 12 AM-6 AM & 24 & 27 & 13 & 8.8 & 5.6 & 7.7 & \\
\hline Injury mechanism $(\%)$ & & & & & & & 0.34 \\
\hline Acceleration/deceleration & 4.2 & 10 & 12 & 24 & 23 & 8.3 & \\
\hline Direct impact to head & 67 & 53 & 56 & 46 & 41 & 33 & \\
\hline Fall $>1$ meter & 17 & 10 & 16 & 15 & 9.1 & 17 & \\
\hline Ground level fall & 8.3 & 23 & 12 & 12 & 23 & 33 & \\
\hline Other & 4.2 & 3.3 & 4 & 2.4 & 4.5 & 8.3 & \\
\hline Category of injury (\%) & & & & & & & 0.10 \\
\hline Transportation & 52 & 38 & 43 & 51 & 52 & 50 & \\
\hline Falls & 15 & 31 & 39 & 34 & 33 & 43 & \\
\hline Violence & 0 & 10 & 11 & 0 & 0 & 7.1 & \\
\hline Sports & 33 & 17 & 7.1 & 15 & 9.5 & 0 & \\
\hline
\end{tabular}

$\mathrm{p}<0.01 ; \dagger \mathrm{p}<0.001$. Data were analyzed using chi-square analyses with Bonferroni post-hoc testing. 
Table 3: mTBI characteristics by age group

\begin{tabular}{|c|c|c|c|c|c|c|c|}
\hline & $\begin{array}{c}16-25 \text { years } \\
(\mathrm{n}=27)\end{array}$ & $\begin{array}{c}\text { 26-35 years } \\
(\mathbf{n}=\mathbf{3 1})\end{array}$ & $\begin{array}{c}\text { 36-45 years } \\
(\mathrm{n}=29)\end{array}$ & $\begin{array}{c}\text { 46-55 years } \\
(\mathrm{n}=42)\end{array}$ & $\begin{array}{c}\text { 56-65 years } \\
\quad(\mathrm{n}=\mathbf{2 4})\end{array}$ & $\begin{array}{c}66+\text { years } \\
(\mathrm{n}=14)\end{array}$ & $p$ value \\
\hline Anterograde amnesia (\%) & 22 & 33 & 28 & 9.5 & 21 & 7.1 & 0.70 \\
\hline Retrograde amnesia (\%) & 56 & 42 & 61 & 29 & 46 & 36 & 0.17 \\
\hline Loss of consciousness (\%) & $48 \%$ & 32 & 45 & 50 & 46 & 71 & 0.55 \\
\hline Altered consciousness (\%) & 69 & 90 & 86 & 86 & 82 & 85 & 0.79 \\
\hline Seizure within 48 hours (\%) & 0 & 3.2 & 0 & 4.8 & 0 & 0 & 0.63 \\
\hline Vomiting within 48 hours (\%) & 23 & 24 & 27 & 6.2 & 5.0 & 15 & 0.49 \\
\hline Admitted to hospital immediately after injury (\%) & 36 & 17 & 31 & 28 & 35 & 43 & 0.54 \\
\hline Emergency room visit immediately after injury $(\%)$ & 48 & 31 & 62 & 56 & 44 & 57 & 0.23 \\
\hline Associated injury (other than head and neck) $(\%)$ & 71 & 52 & 62 & 74 & 77 & 86 & 0.26 \\
\hline Death or severe injury to others as a result of event (\%) & 8.7 & 0 & 7.4 & 0 & 0 & 7.7 & 0.26 \\
\hline
\end{tabular}

$* \mathrm{p}<0.01 ; \uparrow \mathrm{p}<0.001$. Data were analyzed using chi-square analyses with Bonferroni post-hoc testing.

As shown in Figure 1, the middle-aged group (36-45 and 46-55 years) were particularly more likely to report experiencing severe symptoms compared with the oldest patients. The 36 - to 45 -year-old age group reported higher severity of headaches (odds ratio [OR], 5.56; 95\% confidence interval [Cl], 1.51-20.44; $\mathrm{p}=0.01$ ), nausea and vomiting $(\mathrm{OR}, 25.15 ; 95 \% \mathrm{CI}, 2.72-233 ; \mathrm{p}=0.01)$, irritability $(\mathrm{OR}$, 5.65; 95\% CI, 1.57-20.31; $\mathrm{p}=0.01$ ), poor concentration (OR, 4.93;

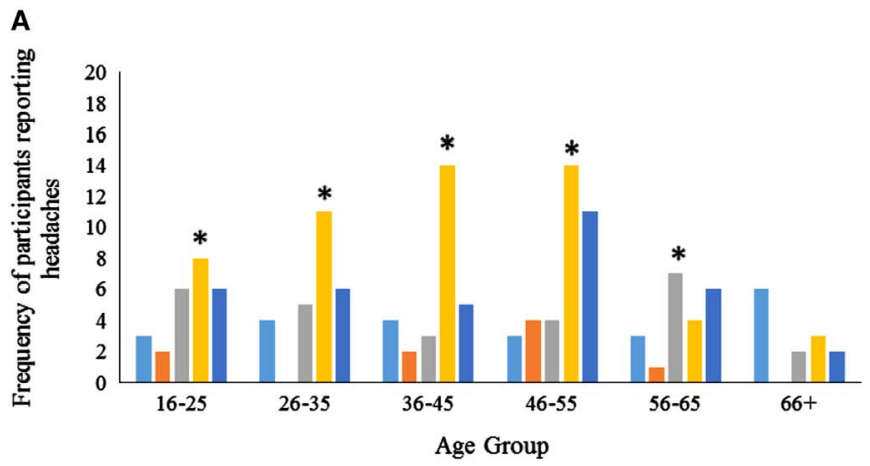

- Not experienced at all $=$ No more of a problem $=$ Mild problem

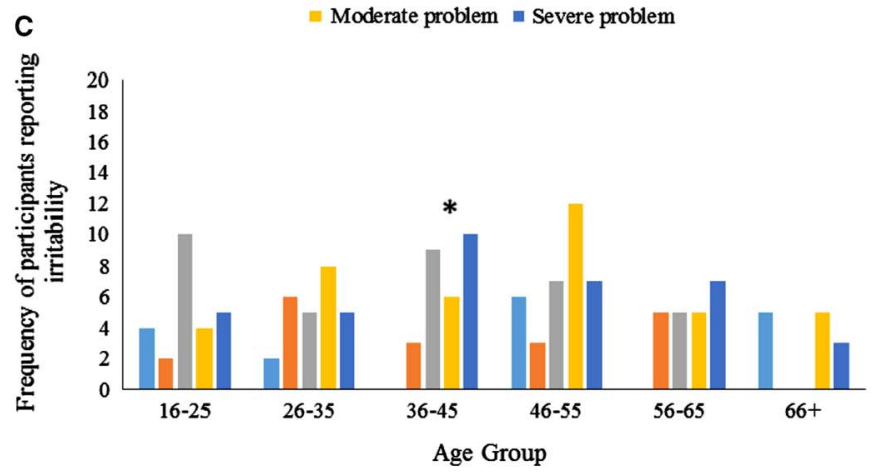

not experienced at all $=$ No more of a problem $\equiv$ Mild problem

= Moderate problem $=$ Severe problem
95\% CI, 1.36-17.81; $\mathrm{p}=0.02)$, and taking longer to think (OR, 4.74; $95 \%$ CI, $1.30-17.20 ; p=0.02$ ) compared with patients $>66$ years of age. As shown in Figure 2, the 46- to 55-year-old age group reported higher severity of sleep disturbance issues (OR, 3.85; 95\% CI, 1.09-13.60; $\mathrm{p}=0.04)$, blurry vision (OR, 4.10; $95 \% \mathrm{CI}, 1.16-14.4 .4$; $\mathrm{p}=0.03$ ), and light sensitivity (OR, 3.80; 95\% CI, 1.09-13.19; $\mathrm{p}=0.04)$ compared with the oldest age group. Also, the 55- to

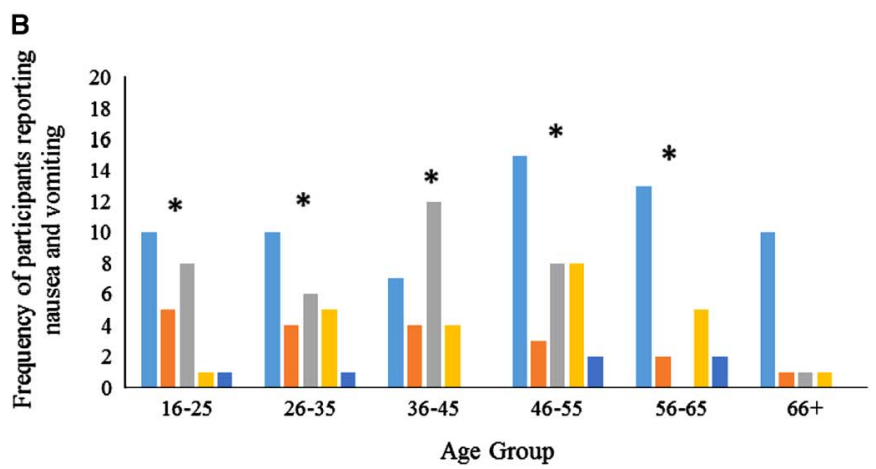

- Not experienced at all $=$ No more of a problem $\mid$ Mild problem

= Moderate problem $=$ Severe problem

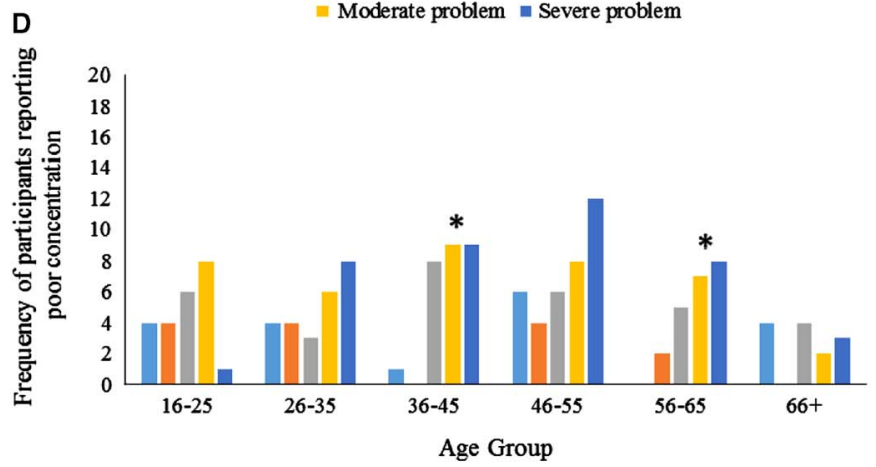

- Not experienced at all $=$ No more of a problem $\|$ Mild problem Moderate problem $=$ Severe problem

Figure 1: All age groups reported significantly higher severity of headaches (A) and nausea and vomiting (B) compared with the 66+ year-old age group. The 36- to 45-year-old age group reported significantly higher severity of irritability $(C)$ and poor concentration $(D)$ post-mTBI compared with the 66+ year old age group. The 56- to 65-year-old age group also reported significantly higher severity of poor concentration post-mTBI compared with the $66+$ year old age group. $* p<0.05$ (ordinal logistic regressions). 

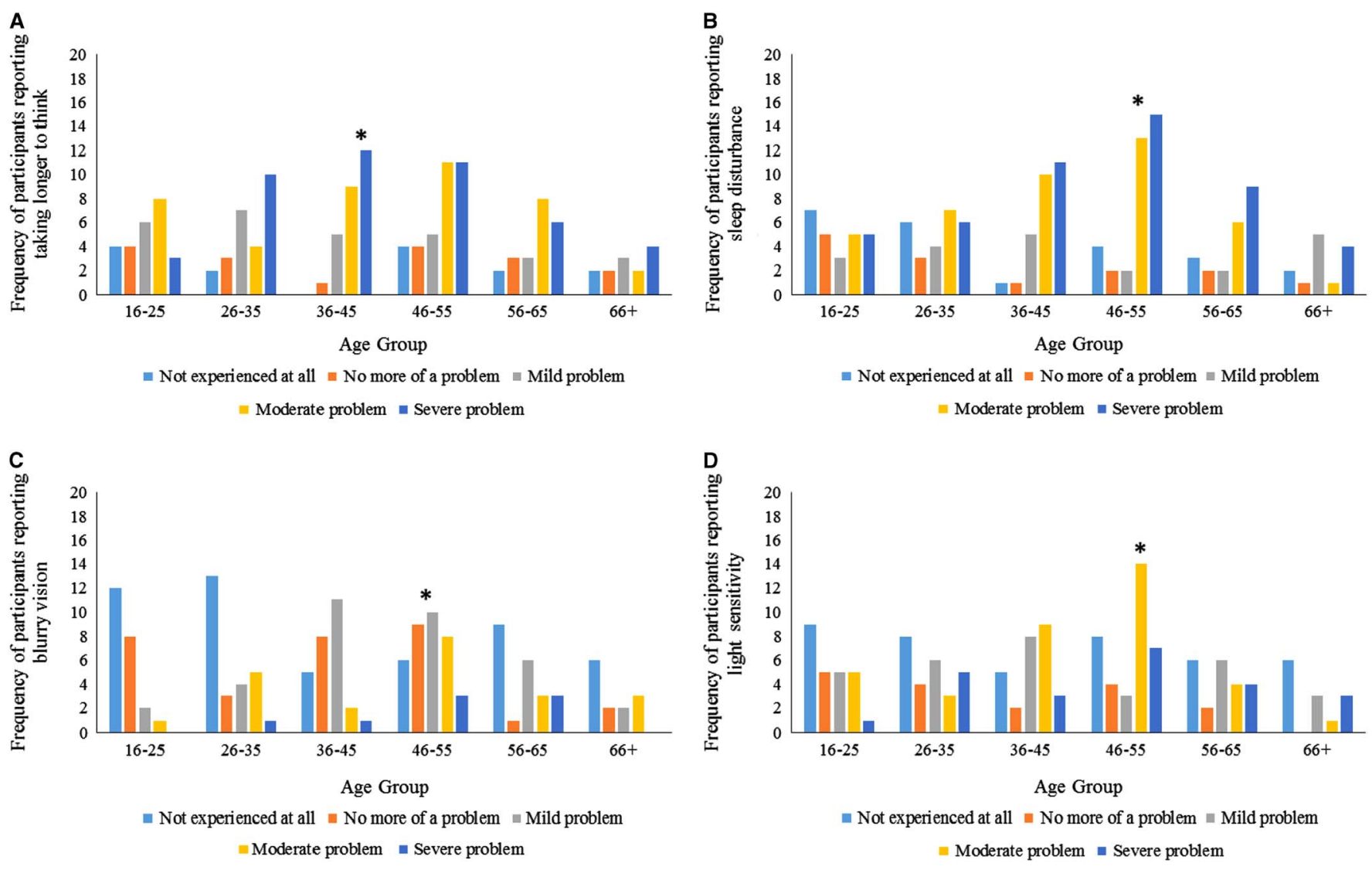

Figure 2: (A) The 36- to 45-year-old age group reported significantly higher severity of taking longer to think post-mTBI compared with the 66+ year old age group. The 46- to 55-year-old age group reported significantly higher severity of sleep disturbances $(B)$, blurry vision (C), and light sensitivity (D) post-mTBI compared with the $66+$ year old age group. $* p<0.05$ (ordinal logistic regressions).

65-year-old age group reported higher severity of concentration issues post-mTBI compared with the oldest age group (OR, 5.01; 95\% CI, 1.33-18.91; $\mathrm{p}=0.02$ ).

As days since the mTBI increased, patients were more likely to report severe headache, nausea and vomiting, sleep disturbance, fatigue, irritability, feeling depressed, feeling frustrated, memory changes, poor concentration, taking longer to think, blurry vision, and double vision ( $\mathrm{p}<0.05$ for all).

Gender was a significant predictor of severity of noise sensitivity post-mTBI, with females being 2.04 times more likely (95\% CI, $0.27-0.89, \mathrm{p}=0.02$ ) to report severe symptoms compared to males.

Injury mechanism was not found to be a significant predictor for the severity of any of the symptoms and was removed from the ordinal regression model.

\section{Predictors of RPQ Subscale Scores}

The average RPQ-3 subscale score was $5.98 \pm 4.14$ and the average RPQ-13 subscale score was $27.7 \pm 12.4$. There were no differences between age groups in RPQ-3 subscale scores ( $p>0.05)$. The middle-aged groups (36-45, 46-55, and 55-65 years) had significantly higher RPQ-13 subscale scores compared with patients $>66$ years of age, $F(5,144)=2.44, \mathrm{p}=0.04$. Days since injury were significant predictors for the RPQ-3 subscale score, $F(1,145)=5.45, \mathrm{p}=0.02, R^{2}=0.04$ and RPQ-13 subscale score, $F(3,143)=5.48, \mathrm{p}=0.001, R^{2}=0.10$.

\section{DISCUSSION}

Our finding that $69 \%$ of mTBI in the elderly ( $>66$ years) occurred in the morning from $6 \mathrm{AM}$ to $12 \mathrm{PM}$ is a new finding not reported in the literature. This result suggests that elderly patients may be at higher risk of mTBI when they wake up in the morning, which may be a result of medications or postural hypotension; however, further research is needed to validate this hypothesis.

We used a validated questionnaire (RPQ) to assess the severity of post-mTBI symptoms in patients at a level 1 tertiary care outpatient HIC. Our findings showed that age was significantly associated with higher severity of certain symptoms post-mTBI. Our study suggests that middle-aged individuals with mTBI (36-55 years) have a higher likelihood of reporting severe symptoms compared with elderly patients for several common mTBI symptoms. Middle-aged patients also had significantly higher RPQ-13 subscale scores, which have been associated with a greater impact on lifestyle, compared with patients $>66$ years of age. ${ }^{25}$ Middle-aged patients may be experiencing more severe symptoms post-mTBI because of additional stressors: in our sample, $92 \%$ to $94 \%$ of the middle-aged patients were employed preinjury and approximately $39 \%$ to $44 \%$ were currently working at the time they were seen at the HIC, which was significantly higher compared with the older age groups. Also, a significant proportion of the middle-aged group (33\%-46\%) was also living with dependents (children $<21$ years), which was higher than all other age groups and may lead to financial and other 
stressors, which may act to increase the severity of post-mTBI symptoms experienced by patients. Another important consideration is baseline functional status pre-mTBI: elderly patients may not perceive the post-mTBI symptoms to be a significant deviation from their regular functioning, whereas younger patients may experience a significant deviation from their regular functioning. Severity of symptoms may be related to the level of cognitive demands placed on patients following mTBI: for example, elderly patients may perceive fewer post-mTBI symptoms because of decreased cognitive demands during retirement, whereas younger patients may perceive more symptoms, which are further exacerbated by stressors and increased demands related to returning to work and school. ${ }^{26}$ The association between age and the likelihood of reporting certain severe symptoms post-mTBI highlights the need for targeted management. This may include earlier referral to specialized services, rehabilitation programs, and more regular follow-up with family physicians for medical management for issues such as chronic headaches, nausea and vomiting, mood changes, and cognitive changes.

As days since the mTBI increased, patients were more likely to report severe headache, nausea and vomiting, sleep disturbance, fatigue, irritability, feeling depressed, feeling frustrated, memory changes, poor concentration, taking longer to think, blurry vision, and double vision. Also, days since mTBI was the only significant predictor of higher RPQ-3 and RPQ-13 subscale scores, which have been shown to have an impact on quality of life. ${ }^{25}$ Days since mTBI is an important variable to consider: research has shown that up to $15 \%$ of patients experience persistent disabling problems and, even 1 year after injury, 22\% are still below functional status. ${ }^{17}$ Lengthy wait times to specialized services and treatment may contribute to the increased severity of symptoms experienced by patients.

Strengths of our study include the use of a validated screening tool for post-mTBI symptom severity and our exploration of various age ranges and the characteristics of patients with mTBI being seen at one of the largest outpatient head injury clinics in Canada. The study has several limitations. The data collected in this study were obtained through self-reporting and thus may be prone to recall bias, which may lead to overestimation or underestimation of symptom severity scores. ${ }^{27}$ Other limitations include not having data regarding previous history of mTBI and post-mTBI depression or mental health conditions, which may impact symptom severity. Last, the population of this study is restricted to patients seen at a tertiary care centre in downtown Toronto and cannot be generalized to all mTBI patients.

\section{CONCLUSIONS}

These findings may have important implications for mTBI management based on age at time of mTBI. Health care providers may wish to consider risk factors that may lead to experiencing greater severity of post-mTBI symptoms and use this information to triage patients on the wait list and to offer earlier referrals to specialized services to manage chronic post-mTBI symptoms. Additional research on the differential effect of age on post-mTBI symptoms would be valuable and help guide clinical assessment and management.

\section{ACKNOWLEDGMENTS AND Funding}

The authors have no funding sources to report.

\section{DisCLOSURES}

$\mathrm{TH}, \mathrm{CH}$, and DO do not have any disclosures.

\section{REFERENCES}

1. Werner C, Engelhard K. Pathophysiology of traumatic brain injury. Br J Anaesth. 2007;99:4-9.

2. Alexander MP. Mild traumatic brain injury: pathophysiology, natural history, and clinical management. Neurology. 1995;45:1253-60.

3. Ryu WH, Feinstein A, Colantonio A, Streiner DL, Dawson DR. Early identification and incidence of mild TBI in Ontario. Can J Neuro Sci. 2009;36:429-35.

4. Cassidy JD, Carroll L, Peloso P, et al. Incidence, risk factors and prevention of mild traumatic brain injury: results of the WHO Collaborating Centre Task Force on Mild Traumatic Brain Injury. J Rehabil Med. 2004;36:28-60.

5. Vanderploeg RD, Curtiss G, Luis CA, Salazar AM. Long-term morbidities following self-reported mild traumatic brain injury. J Clin Exp Neuropsychol. 2007;29:585-98.

6. Faul M, Xu L, Wald MM, Coronado VG. Traumatic brain injury in the United States: emergency department visits, hospitalizations and deaths 2002ГÇô2006. Atlanta, GA: Centers for Disease Control and Prevention, National Center for Injury Prevention and Control; 2010. p. 2-70.

7. Rapoport MJ, Feinstein A. Age and functioning after mild traumatic brain injury: the acute picture. Brain Inj. 2001;15:857-64.

8. Langlois JA, Rutland-Brown W, Thomas KE. Traumatic brain injury in the United States: emergency department visits, hospitalizations, and deaths. Department of Health and Human Services, Centers for Disease Control and Prevention, Division of Acute Care, Rehabilitation Research and Disability Prevention, National Center for Injury Prevention and Control; 2004.

9. Marquez de la Plata C, Hart T, Hammond FM, et al. Impact of age on long-term recovery from traumatic brain injury. Arch Phys Med Rehabil. 2008;89:896-903.

10. Lye TC, Shores EA. Traumatic brain injury as a risk factor for Alzheimer's disease: a review. Neuropsychol Rev. 2000;10:115-29.

11. Tokutomi T, Miyagi T, Ogawa T, et al. Age-associated increases in poor outcomes after traumatic brain injury: a report from the Japan Neurotrauma Data Bank. J Neurotrauma. 2008;25:1407-14.

12. Aharon-Peretz J, Kliot D, Amyel-Zvi E, Tomer R, Rakier A, Feinsod M. Neurobehavioural consequences of closed head injury in the elderly. Brain Inj. 1997;11:871-6.

13. Klein M, Houx PJ, Jolles J. Long-term persisting cognitive sequelae of traumatic brain injury and the effect of age. J Nerv Ment Dis. 1996;184:459-67.

14. Rothweiler B, Temkin NR, Dikmen SS. Aging effect on psychosocial outcome in traumatic brain injury. Arch Phys Med Rehabil. 1998;79:881-7.

15. Rapoport MJ, Feinstein A. Outcome following traumatic brain injury in the elderly: a critical review. Brain Inj. 2000;14:749-61.

16. Goldstein FC, Levin HS, Presley RM, et al. Neurobehavioural consequences of closed head injury in older adults. J Neurol Neurosurg Psychiatry. 1994;57:961-6.

17. McMahon PJ, Hricik A, Yue JK, et al. Symptomatology and functional outcome in mild traumatic brain injury: results from the prospective TRACK-TBI study. J Neurotrauma. 2014;31: 26-33.

18. Breed ST, Flanagan SR, Watson KR. The relationship between age and the self-report of health symptoms in persons with traumatic brain injury. Arch Phys Med Rehabil. 2004;85:61-7.

19. LeBlanc J, Guise Ed, Gosselin N, Feyz M. Comparison of functional outcome following acute care in young, middle-aged and elderly patients with traumatic brain injury. Brain Inj. 2006;20: 779-90.

20. Katz DI, Alexander MP. Traumatic brain injury: predicting course of recovery and outcome for patients admitted to rehabilitation. Arch Neurol. 1994;51:661-70.

21. Kay T. Neuropsychological treatment of mild traumatic brain injury. J Head Trauma Rehabil. 1993;8:74-85.

22. Hicks R, Giacino J, Harrison-Felix C, Manley G, Valadka A, Wilde EA. Progress in developing common data elements for 
traumatic brain injury research: version two-the end of the beginning. J Neurotrauma. 2013;30:1852-61.

23. King NS, Crawford S, Wenden FJ, Moss NEG, Wade DT. The Rivermead Post Concussion Symptoms Questionnaire: a measure of symptoms commonly experienced after head injury and its reliability. J Neurol. 1995;242:587-92.

24. Lannsjo M, Borg J, Bjorklund G, Af Geijerstam JL, Lundgren-Nilsson A. Internal construct validity of the Rivermead Post-concussion Symptoms Questionnaire. J Rehabil Med. 2011;43:997-1002.
25. Eyres S, Carey A, Gilworth G, Neumann V, Tennant A. Construct validity and reliability of the Rivermead post-concussion symptoms questionnaire. Clin Rehabil. 2005;19:878-87.

26. Ponsford J, Willmott CA, Rothwell A, et al. Factors influencing outcome following mild traumatic brain injury in adults. J Int Neuropsychol Soc. 2000;6:568-79.

27. Carroll L, Cassidy JD, Peloso P, et al. Prognosis for mild traumatic brain injury: results of the WHO Collaborating Centre Task Force on Mild Traumatic Brain Injury. J Rehabil Med. 2004;36:84-105. 